\title{
Only true pelagics mix: comparative phylogeography of deepwater bathybatine cichlids from Lake Tanganyika
}

\author{
Stephan Koblmüller 1 - Lukas Zangl • Christine Börger $•$ Daniel Daill • \\ Maarten P. M. Vanhove • Christian Sturmbauer • Kristina M. Sefc
}

Received: 5 March 2018/Revised: 28 June 2018/Accepted: 29 August 2018/Published online: 19 September 2018

(C) The Author(s) 2018

\begin{abstract}
In the absence of dispersal barriers, species with great dispersal ability are expected to show little, if at all, phylogeographic structure. The East African Great Lakes and their diverse fish faunas provide opportunities to test this hypothesis in pelagic fishes, which are presumed to be highly mobile and unrestricted in their movement by physical barriers. Here, we address the link between panmixis and pelagic habitat use by comparing the phylogeographic structure among four deepwater cichlid species of the
\end{abstract}

Handling editor: Sidinei Magela Thomaz

Guest editors: S. Koblmüller, R. C. Albertson, M. J. Genner, K. M. Sefc \& T. Takahashi / Advances in Cichlid Research III: Behavior, Ecology and Evolutionary Biology

Electronic supplementary material The online version of this article (https://doi.org/10.1007/s10750-018-3752-3) contains supplementary material, which is available to authorized users.

S. Koblmüller $(\bowtie) \cdot$ L. Zangl · C. Börger .

D. Daill · C. Sturmbauer · K. M. Sefc

Institute of Biology, University of Graz, Universitätsplatz

2, 8010 Graz, Austria

e-mail: stephan.koblmueller@uni-graz.at

S. Koblmüller

Institute of Vertebrate Biology, Academy of Sciences of the Czech Republic, Května 8, 60365 Brno, Czech

Republic tribe Bathybatini from Lake Tanganyika. We show that the mitochondrial genealogies (based on the most variable part or the control region) of the four species are very shallow $(0.8-4 \%$ intraspecific divergence across entire distribution ranges) and that all species experienced recent population growth. A lack of phylogeographic structure in the two eupelagic species, Bathybates fasciatus and B. leo, was consistent with expectations and with findings in other pelagic cichlid species. Contrary to expectations, a clear phylogeographic structure was detected in the two benthopelagic species, B. graueri and Hemibates stenosoma. Differences in genetic diversity between eupelagic and benthopelagic species may be due to differences in their dispersal propensity, mediated by their respective predatory niches, rather than precipitated by external barriers to dispersal.

D. Daill

Consultants in Aquatic Ecology and Engineering blattfisch e.U., Gabelsbergerstraße 7, 4600 Wels, Austria

M. P. M. Vanhove

Department of Botany and Zoology, Faculty of Science, Masaryk University, Kotlářská 2, 61134 Brno, Czech Republic 
Keywords Cichlidae Bathybates Hemibates .

Panmixis · Pelagic fishes · Phylogeography

\section{Introduction}

Contemporary patterns of genetic diversity and population connectivity within species are influenced by demographic history, historical and present barriers to gene flow, and the species' active and/or passive dispersal ability (Hewitt, 2000; Ellegren \& Galtier, 2016). Thus, highly vagile generalist species with great active dispersal ability typically show little phylogeographic structure, sometimes even across their entire distribution range (e.g., Koblmüller et al., 2012; Statham et al., 2014; Nebel et al., 2015; Pfeiler $\&$ Markow, 2017). This is particularly true for pelagic fishes, which are usually highly mobile with their dispersal not restricted by physical barriers (e.g., Graves \& McDowell, 2003; Theisen et al., 2008; García-Rodríguez et al., 2011), even though exceptions have been reported (e.g., Perrin \& Borsa, 2001; Lu et al., 2006; Fauvelot \& Borsa, 2011; Sebastian et al., 2017).

Vast pelagic freshwater environments are found in the world's largest lakes, including the East African Great Lakes, Tanganyika and Malawi, which are home to extraordinarily species-rich radiations of cichlid fishes (Fryer \& Iles, 1972; Turner et al., 2001; Koblmüller et al., 2008; Salzburger et al., 2014). Even though most of the cichlid diversity is found in the littoral zone, a few lineages have successfully colonized and radiated in the pelagic and benthopelagic habitats (Turner et al., 2004; Koblmüller et al., 2008). Yet, what drives diversification in pelagic cichlids, what the

M. P. M. Vanhove

Research Group Zoology: Biodiversity \& Toxicology, Centre for Environmental Sciences, Hasselt University, Agoralaan Gebouw D, 3590 Diepenbeek, Belgium

M. P. M. Vanhove

Zoology Unit, Finnish Museum of Natural History, University of Helsinki, P.O. Box 17, 00014 Helsinki, Finland

\section{P. M. Vanhove}

Laboratory of Biodiversity and Evolutionary Genomics, Department of Biology, University of Leuven, Ch.

Deberiotstraat 32, 3000 Louvain, Belgium ecological delineators among species are, and how these factors influence dispersal and gene flow, are still poorly understood. Niche partitioning according to food preferences or water depth has been suggested to have played a role (Coulter, 1991; Konings, 1998; Kirchberger et al., 2012; Hahn et al., 2017), as well as, at least for some Lake Malawi species, breeding-site fidelity (Genner et al., 2010a). It is generally assumed that, contrary to stenotopic littoral species which often show significant population differentiation even across minor habitat barriers (e.g., Rico \& Turner, 2002; Sefc et al., 2017a), the eupelagic and benthopelagic species form panmictic populations across an entire lake. Previous studies indeed demonstrated this to be true for a few Lake Malawi species (Diplotaxodon spp.: Shaw et al., 2000, Genner et al., 2010a; Rhamphochromis longiceps: Günther, 1864, Genner et al., 2008) and one Lake Tanganyika species (Boulengerochromis microlepis: Boulenger, 1899, Koblmüller et al., 2015). It is unclear, however, whether this is indeed a general pattern.

Throughout the Pleistocene, faunal communities of Lakes Malawi and Tanganyika were heavily impacted by recurrent climatically induced lake level fluctuations (e.g., Cohen et al., 1997; McGlue et al., 2008; Lyons et al., 2015). Lake levels dropped (and rose) repeatedly by several hundreds of metres in these lakes, and these fluctuations are regarded as an important mechanism driving and synchronizing diversification within and across the lakes (Rossiter, 1995; Sturmbauer et al., 2001; Sefc et al., 2017b). Whereas Lake Malawi remained a single, although very shallow, lake during extreme lake level lowstands, the most dramatic lake level drops may have subdivided Lake Tanganyika into up to four paleolakes, corresponding with current subbasins (Danley et al., 2012; Sturmbauer et al., 2017). These events could potentially have facilitated allopatric diversification in pelagic and benthopelagic cichlids, which might be evident in patterns of speciation and current phylogeographic structure within species. Indeed, support for the influence of past separation(s) of the lake's subbasins comes from the different compositions of their cichlid communities (Van Steenberge et al., 2011).

In the present study, we address the potential links between panmixis and pelagic habitat use by comparing the phylogeographic structure among four species of deepwater cichlids. In Lake Tanganyika, cichlids of the endemic tribe Bathybatini, together with Lates 
perches, large clariid catfishes, and the emperor cichlid (Boulengerochromis microlepis), are the dominant predators in the deep pelagic and benthopelagic habitats down to the limit of the oxygen-bearing layer ( 50-200 m). Currently, this tribe includes seven Bathybates and two Hemibates species, one of which was described only recently (Schedel \& Schliewen, 2017). All bathybatine cichlids feed predominantly on fish, are maternal mouthbrooders, and are sexually dichromatic with silvery females and males that exhibit conspicuous species-specific patterns of blackish spots and stripes on a silvery ground. Apart from the smallest species, B. minor Boulenger, 1906, which barely reaches a total length of $20 \mathrm{~cm}$, all members of the tribe are large species exceeding $30 \mathrm{~cm}$. The Bathybatini are an ancient lineage within Lake Tanganyika's cichlid species flock (Salzburger et al., 2002; Koblmüller et al., 2005; Meyer et al., 2015; Takahashi \& Sota, 2016; Irisarri et al., 2018), and it is assumed that their ancestors colonized the lake as one of the radiation's seeding lineages (Salzburger et al., 2002). The phylogenetic relationships within the tribe are well established (Koblmüller et al., 2005; Kirchberger et al., 2012; Schedel \& Schliewen, 2017). Yet, nothing is known about their phylogeographic or population genetic structure. Such data would increase our knowledge of factors and processes shaping intraspecific diversity in highly mobile (cichlid) fish species. In addition, they may also aid in identifying potentially segregated fish stocks, which is important for conservation and fisheries management. Indeed, some bathybatine species are heavily targeted by local fishermen. Currently, they do not appear to be under immediate threat of overfishing, but data on catch statistics do not exist for any of these species (Petit \& Shipton, 2012).

Here, we characterize the genetic diversity of four bathybatine cichlid species-the eupelagic species Bathybates fasciatus Boulenger, 1901 and B. leo Poll, 1956 that live and prey in the open water zone, and the benthopelagic species B. graueri Steindachner, 1911 and Hemibates stenosoma (Boulenger, 1901) that live and prey above the bottom-and reconstruct their phylogeographic structure and demographic history based on mitochondrial DNA sequences. The findings are discussed in the light of the biological characteristics of the species and the hydrological history of Lake Tanganyika.

\section{Materials and methods}

Fin clips were taken from 28, 63, 25, and 84 individuals of Bathybates fasciatus, B. graueri, B. leo, and Hemibates stenosoma, respectively, obtained at local fish markets in Bujumbura, Uvira and Mpulungu or from artisanal fishermen on the lake, during several field trips between 1992 and 2016 (Fig. 1, Supplementary Table 1), and preserved in 96\% ethanol. Whole genomic DNA was extracted following a rapid Chelex protocol (Richlen \& Barber, 2005). The most variable part of the mitochondrial control region was amplified and sequenced according to the protocols described in Koblmüller et al. (2011) and Duftner et al. (2005), respectively. The primers used for PCR and chain-termination sequencing were L-Pro-F_Tropheus (Koblmüller et al., 2011) and TDK-D (Lee et al., 1995). DNA fragments were purified with Sephadex ${ }^{\mathrm{TM}}$ G-50 (Amersham Biosciences) and visualized on an ABI 3130xl capillary sequencer (Applied Biosystems). Sequences were aligned by eye in MEGA7 (Kumar et al., 2016). The lengths of the final alignments were $354 \mathrm{bp}$ for $B$. fasciatus and B. graueri, $355 \mathrm{bp}$ for B. leo, and $320 \mathrm{bp}$ for $H$. stenosoma. Sequences are deposited in GenBank under the accession numbers listed in Supplementary Table 1.

Haplotype $\left(H_{\mathrm{d}}\right)$ and nucleotide diversity $(\pi)$ were calculated in DnaSP 5.10 (Librado \& Rozas, 2009). Intraspecific phylogenetic relationships among haplotypes were inferred by means of statistical parsimony networks (Templeton et al., 1992) in PopART (Leigh \& Bryant, 2015). To test for signals of past population expansion, mismatch distributions were calculated in Arlequin 3.5.1.2 (Excoffier \& Lischer, 2010). The fit of the observed mismatch distribution to the expectations based on growth parameter estimates was evaluated by the sum of squared differences $(S S D)$ and the raggedness index $(r g)$. In addition, past population size trajectories and time to the most recent common ancestor (tMRCA) were inferred by means of a Bayesian coalescent approach [Bayesian skyline plot (BSP) tree prior] as implemented in BEAST 1.8.4 (Drummond et al., 2012). We employed the model of molecular evolution selected by the Bayesian information criterion (BIC) in jModelTest 0.1 (Posada, 2008) and assumed a strict molecular clock and a substitution rate of 0.0325 and alternatively 0.057 per site per MY (Koblmüller et al., 2009). 


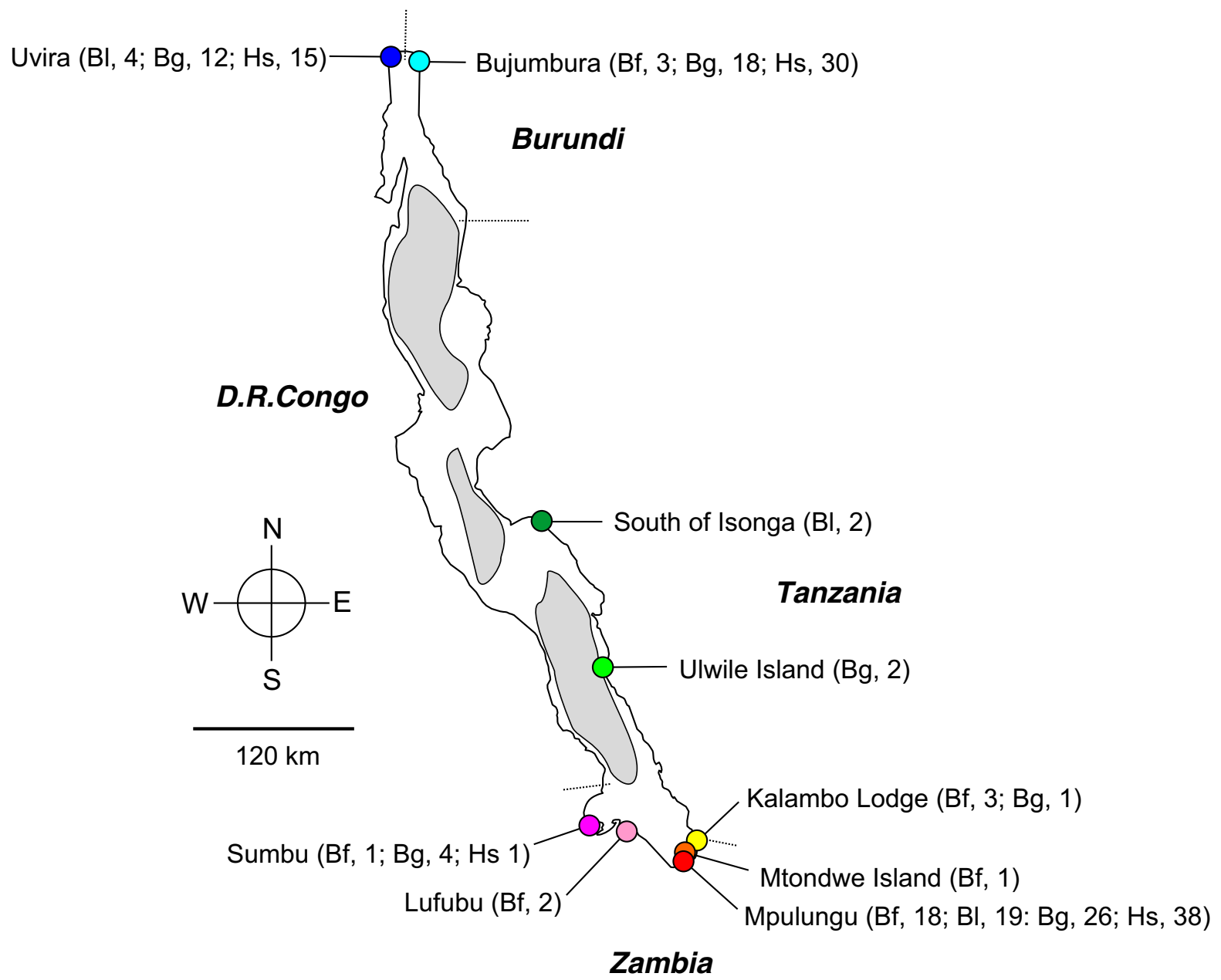

Fig. 1 Map of Lake Tanganyika showing the sampling localities. Number of individual samples per species and locality are given in parentheses. Bf, Bathybates fasciatus; Bl, Bathybates leo; Bg, Bathybates graueri; Hs, Hemibates stenosoma

Two independent MCMC runs of one million generations each were conducted, sampling every 1000th step with a burn-in of the first $10 \%$ of sampled generations. Verification of effective sample sizes [ESS $>200$ for all parameters, indicating that the parameter log file accurately reflected the posterior distribution (Kuhner, 2009)], trace of MCMC runs, and visualization of past demographic changes were done in Tracer 1.5 (Rambaut \& Drummond, 2009).

\section{Results}

Genetic diversity was somewhat higher in the eupelagic species B. fasciatus and B. leo than in the benthopelagic species $B$. graueri and $H$. stenosoma
(Table 1). The number of haplotypes found per species was 10 for B. fasciatus, 4 for B. graueri, 9 for $B$. leo and 16 for $H$. stenosoma. Intraspecific divergence varied among species, with maximum numbers of pairwise differences amounting to 14 in $B$. fasciatus, 4 in B. leo, 3 in B. graueri and 9 in $H$. stenosoma. Whereas the haplotype networks of the eupelagic species indicated no geographic structure (Fig. 2a, b), a clear separation into northern and southern haplotypes became evident in the benthopelagic B. graueri and H. stenosoma (Fig. 2c, d), despite some haplotype sharing between northern and southern samples. Specifically, in B. graueri, the dominant northern and southern haplotypes were also found in two southern and one northern individual(s), respectively (Fig. 2c), and in $H$. stenosoma, two 
Table 1 Sample sizes $(N)$ and genetic diversity estimates for the four target species and distinct geographic clades of Hemibates stenosoma

\begin{tabular}{|c|c|c|c|c|c|}
\hline Species & $N$ & $H$ & $H_{\mathrm{d}}$ & $\pi$ & $\begin{array}{l}\text { Maximum intraspecific } \\
\text { divergence }(\%)\end{array}$ \\
\hline Bathybates fasciatus & 28 & 10 & 0.836 & 0.01330 & 4.0 \\
\hline Bathybates graueri & 63 & 4 & 0.597 & 0.00202 & 0.8 \\
\hline Bathybates leo & 25 & 9 & 0.847 & 0.00419 & 1.1 \\
\hline Hemibates stenosoma all & 84 & 16 & 0.749 & 0.00933 & 2.5 \\
\hline Hemibates stenosoma North $^{\mathrm{a}}$ & 47 & 9 & 0.349 & 0.00143 & 1.1 \\
\hline Hemibates stenosoma South & 37 & 7 & 0.743 & 0.00334 & 1.1 \\
\hline
\end{tabular}

$H$ number of haplotypes, $H_{\mathrm{d}}$ haplotype diversity, $\pi$ nucleotide diversity

${ }^{a}$ This clade also includes two southern samples that cluster within this haplogroup

southern individuals grouped within the northern clade (Fig. 2d).

Signatures of population expansion were detected in all four species. The fits of the observed mismatch distributions to the expectations based on growth parameter estimates, with nonsignificant $S S D$ and $r g$ values, indicated recent population growth in $B$. fasciatus, B. leo, both clades of $B$. graueri and the northern cade of $H$. stenosoma (Fig. 3). In the southern $H$. stenosoma, the presence of two divergent haplotypes caused a more ragged mismatch distribution. However, Bayesian skyline plot reconstructions produced clear evidence for strong recent growth in $H$. stenosoma (both clades pooled), as well as weaker expansions in B. fasciatus and B. leo (Fig. 3). The extremely low intraspecific divergence prevented the estimation of BSPs for B. graueri. The onset of the inferred recent population expansion was dated to about 20-40 KYA, depending on the substitution rate assumed, for B. fasciatus and H. stenosoma, but could not be estimated for $B$. leo because of low intraspecific divergence (Fig. 4). Estimates of the time to the most recent common ancestor differed among the four species and ranged from mean estimates of 22.6-39.7 KYA in B. graueri to 197.2-345.8 KYA in B. fasciatus (Table 2).

\section{Discussion}

Analysis of the most variable region of the mitochondrial control region revealed a lack of phylogeographic structure in the two eupelagic species $B$. fasciatus and B. leo. This is consistent with findings in other pelagic species (e.g., Graves \& McDowell, 2003; Theisen et al., 2008; García-Rodríguez et al., 2011) and the idea that the absence of physical barriers should preclude population structure in highly mobile species (Hartl \& Clark, 1997). Haplotypes of the two benthopelagic species, B. graueri and H. stenosoma, in contrast, were divided into northern and southern clades. Sampling of all four species concentrated on the northernmost and southernmost regions of Lake Tanganyika (Fig. 1) and therefore spanned the largest possible distance $(>700 \mathrm{~km})$ across the lake. Lacking samples from intermittent locations, it is not possible to assess whether the clades of northern and southern B. graueri and $H$. stenosoma represent the endpoints of phylogeographic isolation-by-distance continua or reflect the existence of discrete phylogeographic units. Haplotype sharing between northern and southern clades could therefore indicate either step-wise shortrange or occasional long-range gene flow. Alternatively, given the shallow genetic divergence among clades, particularly in B. graueri, haplotype sharing may simply be a remnant of incomplete lineage sorting.

The observed phylogeographic structure in $B$. graueri and $H$. stenosoma contradicts the assumption that all Bathybates and Hemibates species form panmictic populations across the entire lake (Konings, 1998), and is surprising given the absence of apparent physical barriers to dispersal for benthopelagic species. Therefore, one must implicate ecological distinctions as dispersal restrictions. One potential explanation for the difference in large-scale phylogeographic patterns between the eu- and the benthopelagic bathybatine species might lie in their 


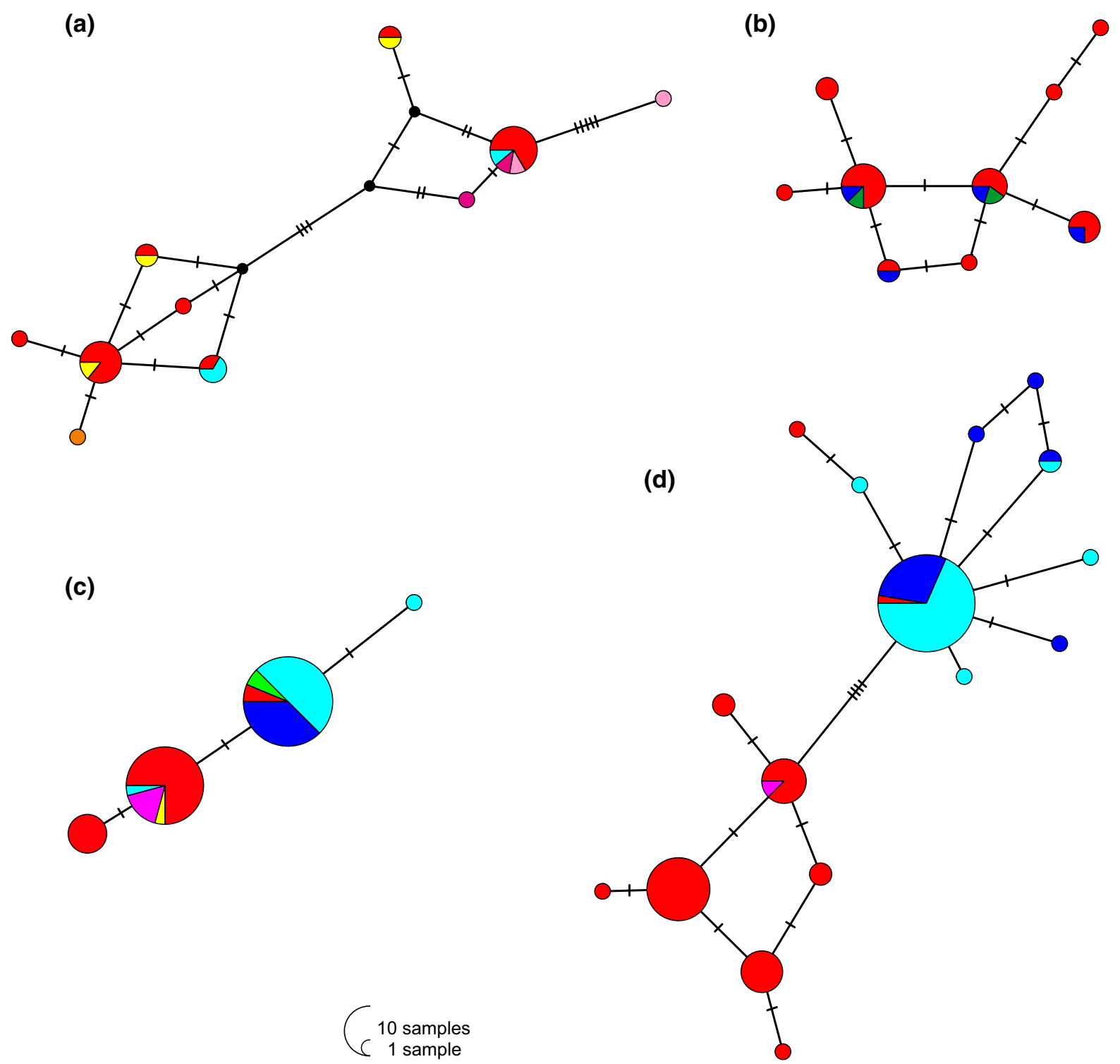

Fig. 2 Statistical parsimony networks of a Bathybates fasciatus, b Bathybates leo, c Bathybates graueri, d Hemibates stenosoma. Circle sizes are proportional to haplotype frequency.

specialization on different types of prey. In pursuit of pelagic prey-mainly the lake's two endemic clupeid species (Coulter, 1991)—Bathybates fasciatus and B. leo-roam the lakes' pelagic zone down to the limit of the oxygen-bearing layer $(\sim 50 \mathrm{~m}$ in the north and $\sim 200 \mathrm{~m}$ in the south of the lake). This specialization on pelagic prey requires these two species to be highly mobile and to move long distances through open water. Bathybates graueri and H. stenosoma are also mainly found at great depth, but they prey upon
Tick marks indicate the number of mutations between haplotypes. Different colors refer to different sampling localities as shown in Fig. 1

benthic and benthopelagic cichlids, in particular the various deepwater Xenotilapia, Limnochromis and Trematocara species (Coulter, 1991). Although some of these prey species, especially Trematocara spp., migrate to shallow waters during night, with $H$. stenosoma and probably also B. graueri in their wake (Coulter, 1991; Konings, 1998), these two predators do not need to move long distances through open water to find their prey. These differences in foraging behavior might translate into different dispersal 
Bathybates fasciatus

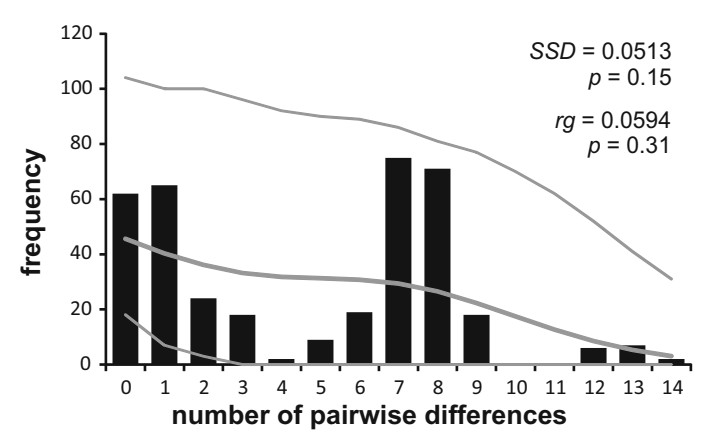

Bathybates leo

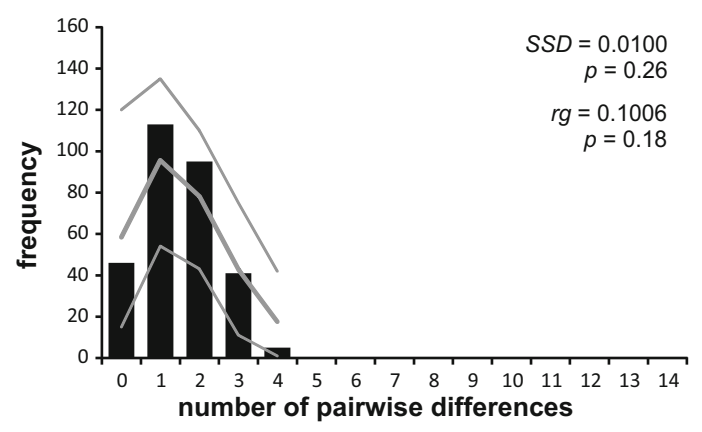

Fig. 3 Mismatch distribution for the four target species and geographic clades within species (if applicable). Black columns represent the observed frequency of pairwise differences. Gray lines refer to the expected distribution based on parameter estimates and their $95 \%$ confidence limits simulated under a

patterns and result in range-wide admixture of the eupelagic hunters versus restricted gene flow in the benthopelagic ones. This contrast cannot be generalized, however: a study of another benthopelagic species from Lake Tanganyika, Boulengerochromis microlepis, showed that a benthopelagic life style per se does not necessarily imply phylogeographic structuring (Koblmüller et al., 2015). Thus, there might be additional ecological features that contribute to dispersal.

Maximum intraspecific divergence varied among the four Bathybatini species from 0.8 to $4 \%$ (Table 1), but was comparable to the lake-wide divergence observed in the benthopelagic Boulengerochromis microlepis (2.5\%, Koblmüller et al., 2015). These divergence estimates are low in comparison to stenotopic littoral species of Lake Tanganyika (Duftner et al., 2007; Koblmüller et al., 2017). Similar values $(2.2-4.2 \%)$ were estimated within individual
Bathybates graueri

North

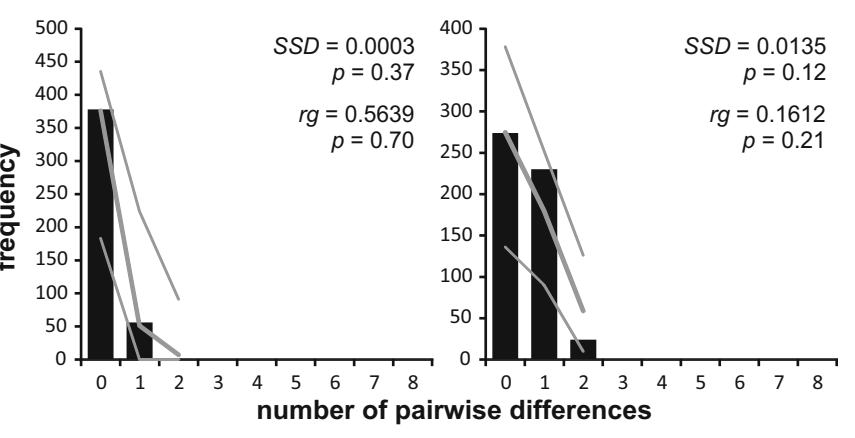

Hemibates stenosoma

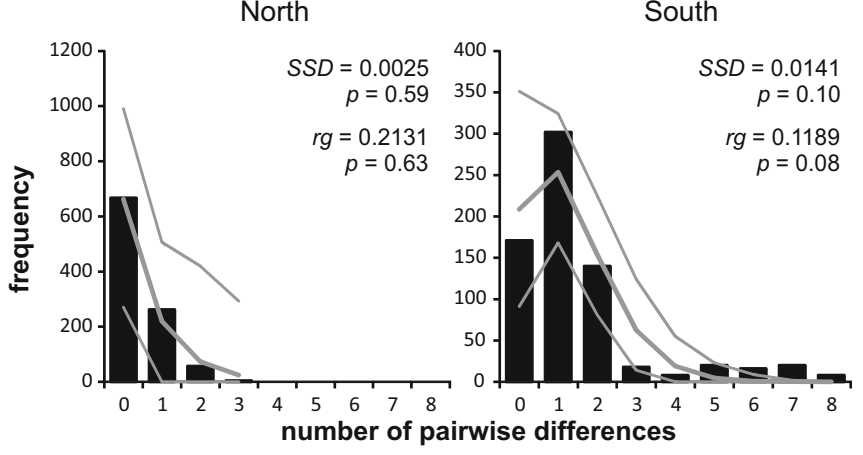

model of population growth. Sum of squared differences $(S S D)$ and raggedness index $(r g)$ and their respective $P$ values are given to describe the fit of the observed mismatch distribution to the expectation based on growth parameter estimates

populations of stenotopic littoral species (Duftner et al., 2006; Koblmüller et al., 2007, 2009; Sefc et al., 2007). So far, among Lake Tanganyika cichlids, the pattern of large intraspecific divergence in geographically highly structured littoral species versus low intraspecific divergence in highly vagile eu- and benthopelagic deepwater species has been confirmed without exception.

Recent population expansion has turned out as a commonality among the cichlids of Lake Malawi and Tanganyika (littoral, e.g., Genner et al., 2010b; Koblmüller et al., 2011; Genner \& Turner, 2015; Husemann et al., 2015; Sturmbauer et al., 2017; Winkelmann et al., 2017; deepwater: Genner \& Turner, 2015; Koblmüller et al., 2015). In littoral species, demographic fluctuations are expected to be tied-up with habitat shrinkage and expansion during lake level fluctuations, and indeed, the reconstructed population expansions are temporally aligned with the 


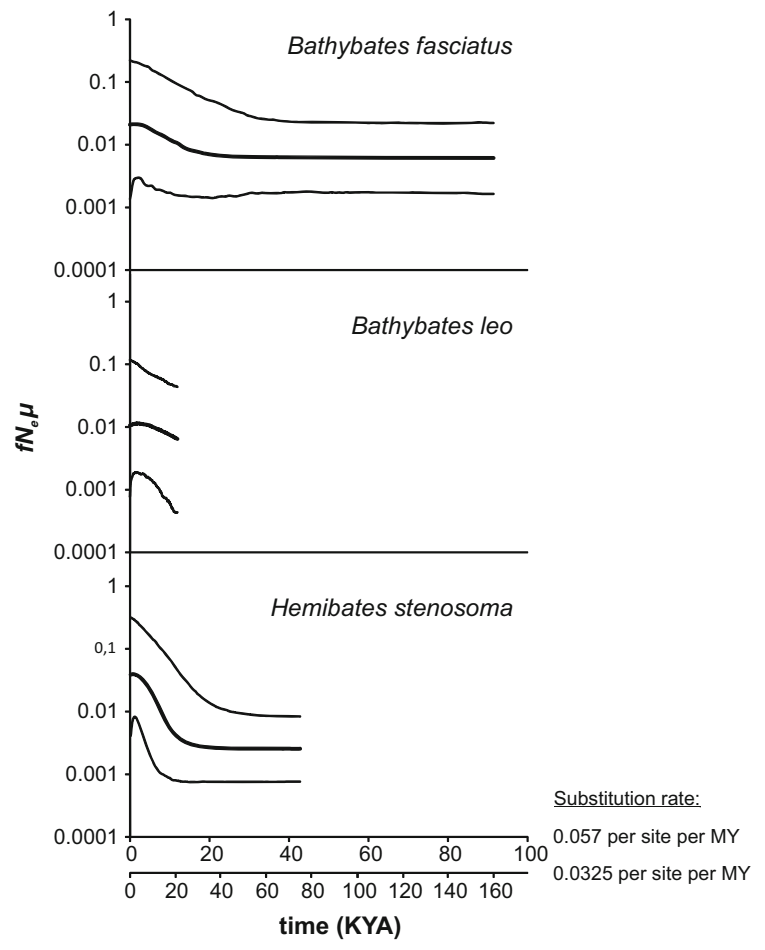

Fig. 4 Bayesian skyline plots (BSP) of past population size trajectories assuming minimum and maximum substitution rates of 3.25 and $5.7 \%$ per site per MY (Koblmüller et al., 2009). Thick lines denote median estimate; thin lines indicate $95 \%$ highest posterior density (HPD) intervals. The y-axis represents the population size parameter (product of female effective population size, $f N_{\mathrm{e}}$, and mutation rate, $\mu$ )

most recent lake level rises after the last glacial maximum (McGlue et al., 2008). The demographic histories of eu- and benthopelagic species have been assumed to be less impacted by lake level fluctuations.

Table 2 Time to most recent common ancestor (tMRCA) of the four target species and the two distinct clades within Hemibates stenosoma, inferred based on minimum and
In fact, population growth in these species was typically not as strong as in littoral cichlids and occurred earlier (Genner \& Turner, 2015; Koblmüller et al., 2015), which suggests that only the most severe lake level fluctuation had a significant impact on the population size trajectories of eu- and benthopelagic species. In contrast, the dating of the population expansions of the bathybatine cichlid species studied here is more similar to that in littoral Lake Tanganyika cichlids (e.g., Koblmüller et al., 2011, 2017; Sefc et al., 2017a; Sturmbauer et al., 2017; Winkelmann et al., 2017). As in the previous studies, our time estimates are subject to the time dependency of the molecular clock (Ho et al., 2007) and uncertainty about substitution rates and appropriate calibration points (discussed in Koblmüller et al., 2017). However, since estimates from the various cichlid species were obtained under similar conditions, these values can be readily compared across species. Intriguingly, signatures of recent population expansion were also detected in a monogenean gill parasite of Bathybates and Hemibates (Kmentová et al., 2016), suggesting concurrent population expansion in hosts and parasites.

In summary, we show that the mitochondrial genealogies of B. fasciatus, B. graueri, B. leo and $H$. stenosoma are very shallow and that all species experienced recent population growth. A clear phylogeographic structure is present only in the benthopelagic species $B$. graueri and $H$. stenosoma. Differences in genetic diversity between eu- and benthopelagic species may be due to differences in their dispersal propensity, mediated by their respective

maximum assumed substation rates of 3.25 and $5.7 \%$ per million years, respectively (Koblmüller et al., 2009)

\begin{tabular}{lcc}
\hline Species & \multicolumn{1}{c}{ tMRCA (95\% HPD) } & \\
\cline { 2 - 3 } & $3.25 \%$ & $5.7 \%$ \\
\hline Bathybates fasciatus & $345,841(160,409-555,496)$ & $197,190(91,461-316,730)$ \\
Bathybates graueri & $39,705(1,262-100,690)$ & $22,639(720-57,411)$ \\
Bathybates leo & $84,884(21,123-167,608)$ & $48,399(12,044-95,566)$ \\
Hemibates stenosoma all & $220,704(74,717-394,686)$ & $125,840(42,602-225,040)$ \\
Hemibates stenosoma North $^{\mathrm{a}}$ & $80,129(22,191-155,887)$ & $45,688(12,653-88,883)$ \\
Hemibates stenosoma South & $62,870(19,054-123,116)$ & $35,847(10,864-70,768)$ \\
\hline
\end{tabular}

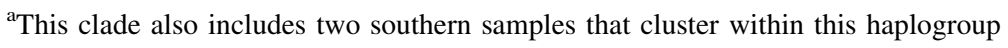


predatory niches, rather than different physical barriers to dispersal.

Acknowledgements Open access funding provided by Austrian Science Fund (FWF). This study was supported by an incentive grant of the Institute of Zoology, University of Graz to SK. SK and MPMV were further supported by the Czech Science Foundation (GBP505/12/G112-ECIP). Additional financial support was provided by the Austrian Science Foundation (FWF) - Grant Nos. P27605-B25 and P22737-B09 to KMS and CS-respectively. The authors would like to thank the following people for their contribution to organizing the field work: J. ( $\dagger$ ) and M. Schreyen-Brichard and the technical staff of Fishes of Burundi, C. Amundala Shekani, G. Banyankimbona, J. Mbirize Ndalozibwa, T. Mulimbwa N'sibula, F. Muterezi Bukinga, D. Muzumani Risasi, H. Phiri, D. Sinyinza, L. Makasa, I. Přikrylová, A. Šimková, and M. Gelnar. We further thank W. Salzburger and B. Egger for providing some tissue samples.

Open Access This article is distributed under the terms of the Creative Commons Attribution 4.0 International License (http:// creativecommons.org/licenses/by/4.0/), which permits unrestricted use, distribution, and reproduction in any medium, provided you give appropriate credit to the original author(s) and the source, provide a link to the Creative Commons license, and indicate if changes were made.

\section{References}

Cohen, A. S., K.-E. Lezzar, J.-J. Tiercelin \& M. Soreghan, 1997. New palaeogeographic and lake-level reconstructions of Lake Tanganyika: implications for tectonic, climatic and biological evolution in a rift lake. Basin Research 9: 107-132.

Coulter, G. W., 1991. Lake Tanganyika and Its Life. Oxford University Press, Oxford.

Danley, P. D., M. Husemann, B. Ding, L. M. DiPietro, E. J. Beverly \& D. J. Peppe, 2012. The impact of the geologic history and paleoclimate on the diversification of East African cichlids. International Journal of Evolutionary Biology 2012: 574851.

Drummond, A. J., M. A. Suchard, D. Xie \& A. Rambaut, 2012. Bayesian phylogenetics with BEAUti and the BEAST 1.7. Molecular Biology and Evolution 29: 1969-1973.

Duftner, N., S. Koblmüller \& C. Sturmbauer, 2005. Evolutionary relationships of the Limnochromini, a tribe of benthic deepwater cichlid fish endemic to Lake Tanganyika, East Africa. Journal of Molecular Evolution 60: 277-289.

Duftner, N., K. M. Sefc, S. Koblmüller, B. Nevado, E. Verheyen, H. Phiri \& C. Sturmbauer, 2006. Distinct population structure in a phenotypically homogeneous rock-dwelling cichlid fish from Lake Tanganyika. Molecular Ecology 15: 2381-2396.

Duftner, N., K. M. Sefc, S. Koblmüller, W. Salzburger, M. Taborsky \& C. Sturmbauer, 2007. Parallel evolution of facial stripe patterns in the Neolamprologus brichardil pulcher species complex endemic to Lake Tanganyika. Molecular Phylogenetics and Evolution 45: 706-715.

Ellegren, H. \& N. Galtier, 2016. Determinants of genetic diversity. Nature Reviews Genetics 17: 422-433.

Excoffier, L. \& H. E. Lischer, 2010. Arlequin suite ver 3.5: a new series of programs to perform population genetic analyses under Linux and Windows. Molecular Ecology Resources 10: 564-567.

Fauvelot, C. \& P. Borsa, 2011. Patterns of genetic isolation in a widely distributed pelagic fish, the narrow-barred Spanish mackerel (Scomberomorus commerson). Biological Journal of the Linnean Society 104: 886-902.

Fryer, G. \& T. D. Iles, 1972. The Cichlid Fishes of the Great Lakes of Africa. T.H.F, Neptune.

García-Rodríguez, F. J., S. A. García-Gasca, J. D. La CruzAgüero \& V. M. Cota-Gómez, 2011. A study of the population structure of the Pacific sardine Sardinops sagax (Jenyns, 1842) in Mexico based on morphometric and genetic analyses. Fisheries Research 107: 169-176.

Genner, M. J., P. Nichols, P. W. Shaw, G. R. Carvalho, R. L. Robinson \& G. F. Turner, 2008. Genetic homogeneity among breeding grounds and nursery areas of an exploited Lake Malawi cichlid fish. Freshwater Biology 53: 1823-1831.

Genner, M. J., P. Nichols, P. W. Shaw, G. R. Carvalho, R. L. Robinson \& G. F. Turner, 2010a. Population structure on breeding grounds of Lake Malawi's 'twilight zone' cichlid fishes. Journal of Biogeography 37: 258-269.

Genner, M. J., M. E. Knight, M. P. Haeseler \& G. F. Turner, 2010b. Establishment and expansion of Lake Malawi rock fish populations after a dramatic Late Pleistocene lake level rise. Molecular Ecology 19: 170-182.

Genner, M. J. \& G. F. Turner, 2015. Timing of population expansions within the Lake Malawi haplochromine cichlid fish radiation. Hydrobiologia 748: 121-132.

Graves, J. E. \& J. R. McDowell, 2003. Stock structure of the world's istiophorid billfishes: a genetic perspective. Marine and Freshwater Research 54: 287-298.

Hahn, C., M. J. Genner, G. F. Turner \& D. A. Joyce, 2017. The genomic basis of cichlid fish adaptation within the deepwater "twilight zone" of Lake Malawi. Evolution Letters 1: 184-198.

Hartl, D. L. \& G. C. Clark, 1997. Principles of Population Genetics, 3rd ed. Sinauer Associates, Sunderland.

Hewitt, G., 2000. The genetic legacy of the Quaternary ice ages. Nature 405: 907-913.

Ho, S. Y. W., B. Shapiro, M. J. Phillips, A. Cooper, A. J. Drummond \& J. Sullivan, 2007. Evidence for time dependency of molecular rate estimates. Systematic Biology 56: 515-522.

Husemann, M., R. Nguyen, B. Ding \& P. D. Danley, 2015. A genetic demographic analysis of Lake Malawi rockdwelling cichlids using spatio-temporal sampling. Molecular Ecology 24: 2686-2701.

Irisarri, I., P. Singh, S. Koblmüller, J. Torres-Dowdall, F. Henning, P. Franchini, C. Fischer, A. R. Lemmon, E. Moriarty Lemmon, G. G. Thallinger, C. Sturmbauer \& A. Meyer, 2018. Phylogenomics uncovers early hybridization and adaptive loci shaping the radiation of Lake Tanganyika cichlid fishes. Nature Communications 9: 3159. 
Kirchberger, P. C., K. M. Sefc, C. Sturmbauer \& S. Koblmüller, 2012. Evolutionary history of Lake Tanganyika's predatory deepwater cichlids. International Journal of Evolutionary Biology 2012: 716209.

Kmentová, N., M. Gelnar, M. Mendlová, M. Van Steenberge, S. Koblmüller \& M. P. M. Vanhove, 2016. Reduced hostspecificity in a parasite infecting non-littoral Lake Tanganyika cichlids evidenced by intraspecific morphological and genetic diversity. Sientific Reports 6: 39605 .

Koblmüller, S., N. Duftner, C. Katongo, H. Phiri \& C. Sturmbauer, 2005. Ancient divergence in bathypelagic Lake Tanganyika deepwater cichlids: mitochondrial phylogeny of the tribe Bathybatini. Journal of Molecular Evolution 60: 297-314.

Koblmüller, S., K. M. Sefc, N. Duftner, M. Warum \& C. Sturmbauer, 2007. Genetic population structure as indirect measure of dispersal ability in a Lake Tanganyika cichlid. Genetica 130: 121-131.

Koblmüller, S., K. M. Sefc \& C. Sturmbauer, 2008. The Lake Tanganyika cichlid species assemblage: recent advances in molecular phylogenetics. Hydrobiologia 615: 5-20.

Koblmüller, S., N. Duftner, K. M. Sefc, U. Aigner, M. Rogetzer \& C. Sturmbauer, 2009. Phylogeographic structure and gene flow in the scale-eating cichlid Perissodus microlepis (Teleostei, Perciformes, Cichlidae) in southern Lake Tanganyika. Zoologica Scripta 38: 257-268.

Koblmüller, S., W. Salzburger, B. Obermüller, E. Eigner, C. Sturmbauer \& K. M. Sefc, 2011. Separated by sand, fused by dropping water: habitat barriers and fluctuating water levels steer the evolution of rock-dwelling cichlid populations. Molecular Ecology 20: 2272-2290.

Koblmüller, S., R. K. Wayne \& J. A. Leonard, 2012. Impact of Quaternary climatic changes and interspecific competition on the demographic history of a highly mobile generalist carnivore, the coyote. Biology Letters 8: 644-647.

Koblmüller, S., E. A. Odhiambo, D. Sinyinza, C. Sturmbauer \& K. M. Sefc, 2015. Big fish, little divergence: phylogeography of Lake Tanganyika's giant cichlid, Boulengerochromis microlepis. Hydrobiologia 748: 29-38.

Koblmüller, S., B. Nevado, L. Makasa, M. Van Steenberge, M. P. M. Vanhove, E. Verheyen, C. Sturmbauer \& K. M. Sefc, 2017. Phylogeny and phylogeography of Altolamprologus: ancient introgression and recent divergence in a rockdwelling Lake Tanganyika cichlid genus. Hydrobiologia 791: 35-50.

Konings, A., 1998. Tanganyika Cichlids in Their Natural Habitat. Cichlid Press, El Paso.

Kuhner, M. K., 2009. Coalescent genealogy samplers: windows into population history. Trends in Ecology and Evolution 24: 86-93.

Kumar, S., G. Stecher \& K. Tamura, 2016. MEGA7: molecular evolutionary genetics anaylsis verion 7.0 for bigger datasets. Molecular Biology and Evolution 33: 1870-1874.

Lee, W.-J., J. Conroy, W. H. Howell \& T. D. Kocher, 1995. Structure and evolution of the teleost mitochondrial control region. Journal of Molecular Evolution 41: 54-66.

Leigh, J. W. \& D. Bryant, 2015. POPART: full-feature software for haplotype network construction. Methods in Ecology and Evolution 6: 1110-1116.
Librado, P. \& J. Rozas, 2009. DnaSP v5: a software for comprehensive analysis of DNA polymorphism data. Bioinformatics 25: 1451-1452.

Lu, C. P., C. A. Chen, C. Hui, Y. Tzeng \& S. Yeh, 2006. Population genetic structure of the swordfish, Xiphias gladius, in the Indian Ocean and West Pacific inferred from complete DNA sequence of the mitochondrial control region. Zoological Studies 45: 269-279.

Lyons, R. P., C. A. Scholz, A. S. Cohen, J. W. King, E. T. Brown, S. J. Ivory, T. C. Johnson, A. L. Deino, P. N. Reinthal, M. M. McGlue \& M. W. Blome, 2015. Continuous 1.3-million-year record of East African hydroclimate, and implications for patterns of evolution and biodiversity. Proceedings of the national Academy of Sciences 112: 15568-15573.

McGlue, M. M., K. E. Lezzar, A. S. Cohen, J. M. Russell, J.-J. Tiercelin, A. A. Felton, E. Mbede \& H. H. Nkotagu, 2008. Seismic records of late Pleistocene aridity in Lake Tanganyika, tropical East Africa. Journal of Paleolimnology 40: 635-653.

Meyer, B. S., M. Matschiner \& W. Salzburger, 2015. A tribal level phylogeny of Lake Tanganyika cichlid fishes based on a genomic multi-marker approach. Molecular Phylogenetics and Evolution 83: 56-71.

Nebel, C., A. Gamauf, E. Haring, G. Segelbacher, A. Villers \& F. E. Zachos, 2015. Mitochondrial DNA analysis reveals Holarctic homogeneity and a distinct Mediterranean lineage in the Golden eagle (Aquila chrysaetos). Biological Journal of the Linnean Society 116: 328-340.

Perrin, C., \& P. Borsa, 2001. Mitochondrial DNA analysis of the geographic structure of Indian scad mackerel, Decapterus russellii (Carangidae) in the Indo-Malay archipelago. Journal of Fish Biology 59: 1421-1426

Petit, P., \& T. Shipton, 2012. IUU fishing on Lake Tanganyika. Report SF/2012/15. Food and Agriculture Organization of the United Nations \& Indian Ocean Commission.

Pfeiler, E. \& T. A. Markow, 2017. Population connectivity and genetic diversity in long-distance migrating insects: divergent patterns in representative butterflies and dragonflies. Biological Journal of the Linnean Society 122: 479-486.

Posada, D., 2008. jModelTest: phylogenetic model averaging. Molecular Biology and Evolution 25: 1253-1256.

Rambaut, A. \& A. J. Drummond, 2009. Tracer v1.5 [available on internet at http://beast.bio.ed.ac.uk/Tracer].

Richlen, M. L. \& P. H. Barber, 2005. A technique fort the rapid extraction of microalgal DNA from single live and preserved cells. Molecular Ecology Notes 5: 688-691.

Rico, C. \& G. F. Turner, 2002. Extreme microallopatric divergence in a cichlid species from Lake Malawi. Molecular Ecology 11: 1585-1590.

Rossiter, A., 1995. The cichlid fish assemblages of Lake Tanganyika: ecology, behavior and evolution of its species flock. Advances in Ecological Research 26: 187-252.

Salzburger, W., A. Meyer, S. Baric, E. Verheyen \& C. Sturmbauer, 2002. Phylogeny of the Lake Tanganyika cichlid species flock and its relationships to Central- and East African haplochromine cichlid fish faunas. Systematic Biology 51: 113-135.

Salzburger, W., B. Van Bocxlaer \& A. S. Cohen, 2014. Ecology and evolution of the African Great Lakes and their faunas. 
Annual Review of Ecology, Evolution, and Systematics 45: 519-545.

Schedel, F. D. \& U. K. Schliewen, 2017. Hemibates koningsi spec. nov: a new deep-water cichlid (Teleostei: cichlidae) from Lake Tanganyika. Zootaxa 4312: 92-112.

Sebastian, W., S. Sukumaran, P. U. Zacharia \& A. Gopalakrishnan, 2017. Genetic population structure of Indian oil sardine, Sardinella longiceps assessed using microsatellite markers. Conservation Genetics 18: 951-964.

Sefc, K. M., S. Baric, W. Salzburger \& C. Sturmbauer, 2007. Species-specific population structure in rock-specialized sympatric cichlid species in Lake Tanganyika, East Africa. Journal of Molecular Evolution 64: 33-49.

Sefc, K. M., K. Mattersdorfer, C. M. Hermann \& S. Koblmüller, 2017a. Past lake shore dynamics explain present pattern of unidirectional introgression across a habitat barrier. Hydrobiologia 791: 69-82.

Sefc, K. M., K. Mattersdorfer, A. Ziegelbecker, N. Neuhüttler, O. Steiner, W. Goessler \& S. Koblmüller, 2017b. Shifting barriers and phenotypic diversification by hybridization. Ecology Letters 20: 651-662.

Shaw, P. W., G. F. Turner, M. R. Idid, R. L. Robinson \& G. R. Carvalho, 2000. Genetic population structure indicates sympatric speciation of Lake Malawi pelagic cichlids. Proceedings of the Royal Society London Series B, Biological Sciences 267: 2273-2280.

Statham, M. J., J. Murdoch, J. Janecka, K. B. Aubry, C. J. Edwards, C. D. Soulsbury, O. Berry, Z. Wang, D. Harrison, M. Pearch, L. Tomsett, J. Chupasko \& B. J. Sacks, 2014. Range-wide multilocus phylogeography of the red fox reveals ancient continental divergence, minimal genomic exchange and distinct demographic histories. Molecular Ecology 23: 4813-4830.

Sturmbauer, C., S. Baric, W. Salzburger, L. Rüber \& E. Verheyen, 2001. Lake level fluctuations synchronize synchronize genetic divergence of cichlid fishes in African lakes. Molecular Biology and Evolution 18: 144-154.
Sturmbauer, C., C. Börger, M. Van Steenberge \& S. Koblmüller, 2017. A separate lowstand lake at the northern edge of Lake Tanganyika? Evidence from phylogeographic patterns in the cichlid genus Tropheus. Hydrobiologia 791: 51-68.

Takahashi, T. \& T. Sota, 2016. A robust phylogeny among major lineages of the East African cichlids. Molecular Phylogenetics and Evolution 100: 234-242.

Templeton, A. R., K. A. Crandall \& C. F. Sing, 1992. A cladistic analysis of phentotypic associations with haplotypes inferred from restriction endonuclease mapping and DNA sequence data III. Cladogram estimation. Genetics 132: 619-633.

Theisen, T. C., B. W. Bowen, W. Lanier \& J. D. Baldwin, 2008. High connectivity on a global scale in the pelagic wahoo, Acathacybrium solandri (tuna family Scombridae). Molecular Ecology 17: 4233-4247.

Turner, G. F., O. Seehausen, M. E. Knight, C. J. Allender \& R. L. Robinson, 2001. How many species of cichlid fishes are there in African lakes? Molecular Ecology 10: 293-806.

Turner, G. F., R. L. Robinson, P. W. Shaw, G. R. Carvalho \& J. Snoeks, 2004. Identification and biology of Diplotaxodon, Rhamphochromis and Pallidochromis. In Snoeks, J. (ed.), The Cichlid Diversity of Lake Malawi/Nyasa/Niassa: Identification, Distribution and Taxonomy. Cichlid Press, El Paso: 198-251.

Van Steenberge, M., M. P. M. Vanhove, D. M. Risasi, T. M. Nsibula, F. Muterezi Bukings, A. Pariselle, C. Gillardin, E. Vreven, J. A. M. Raeymaekers, T. Huyse, F. A. M. Volckaert, V. Nshombo Muderhwa \& J. Snoeks, 2011. A recent inventory of the fishes of the north-western and central western coast of Lake Tanganyika (Democratic Republic Congo). Acta Ichthyologica et Piscatoria 41: 201-214.

Winkelmann, K., L. Rüber \& M. J. Genner, 2017. Lake level fluctuations and divergence of cichlid fish ecomorphs in Lake Tanganyika. Hydrobiologia 791: 21-34. 